\title{
ENVIRONMENTAL PERFORMANCE OF THERMOSYPHONIC DOMESTIC SOLAR HOT WATER SYSTEMS UNDER DIFFERENT CLIMATIC CONDITIONS: A CASE STUDY FOR GREECE
}

\author{
G. TSILINGIRIDIS* \\ G. MARTINOPOULOS \\ N. KYRIAKIS
}

\author{
Process Equipment Design Laboratory (PEDL) \\ Department of Mechanical Engineering \\ Aristotle University of Thessaloniki \\ P.O.B. 487, GR 54124 , \\ Thessaloniki, Greece
}

* to whom all correspondence should be addressed:

\begin{abstract}
Undoubtedly, sun is the cleanest energy source. Specific systems are needed however for the collection and transformation of solar energy and the manufacturing processes of such systems, as well as the production of the raw materials required, are associated with impacts to the environment. As a result, the life cycle environmental impact of solar systems depends on the type and the size of the systems. System characteristics and also the climate of the installation area, affect the substituted conventional energy (solar coverage). In this paper, the net environmental gain of flat plate thermosyphonic solar systems for domestic use is determined, accounting for the household size (different collector sizes) and the installation area (different solar coverage and transportation distance) for the major cities of Greece. Calculations are based on the "Eco-Indicator "99" methodology and database and it is proved that substituting electricity with solar energy is always environmentally beneficial for systems installed in all major cities of Greece.
\end{abstract}

KEYWORDS: solar energy, solar hot water systems, Ica, environmental impacts

\section{INTRODUCTION}

About $94 \%$ of the manmade $\mathrm{CO}_{2}$ emissions in Europe are attributed to the energy sector as a whole, the fossil fuels being the prime culprits with oil consumption accounting for $50 \%$, natural gas for $22 \%$ and coal for $28 \%$. In terms of activity, electricity and steam generation sectors are responsible for $37 \%$ of $\mathrm{CO}_{2}$ production, transport for $28 \%$, households for $14 \%$, industry for $16 \%$ and the services sector for 5\% (European Commission, 1999).

Key factor in the global warming fight is the rational use of energy and the further utilization of renewable energy sources (RES). In the White
Paper for the Community Strategy and Action Plan (European Commission, 1997), European Commission sets an indicative objective of $12 \%$ contribution of RES to the EU's final energy mix by 2010 , with the "Campaign to Take-Off" (CTO) setting mid-way targets for 2003.

Regarding solar energy utilization, the targets set at EU level are:

- CTO: $15.000 .000 \mathrm{~m}^{2}$ of solar collectors installed by $2003\left(10.000 .000 \mathrm{~m}^{2}\right.$ having already been installed by 2000),

- White Paper: $100.000 .000 \mathrm{~m}^{2}$ of solar collectors installed by 2010 . 


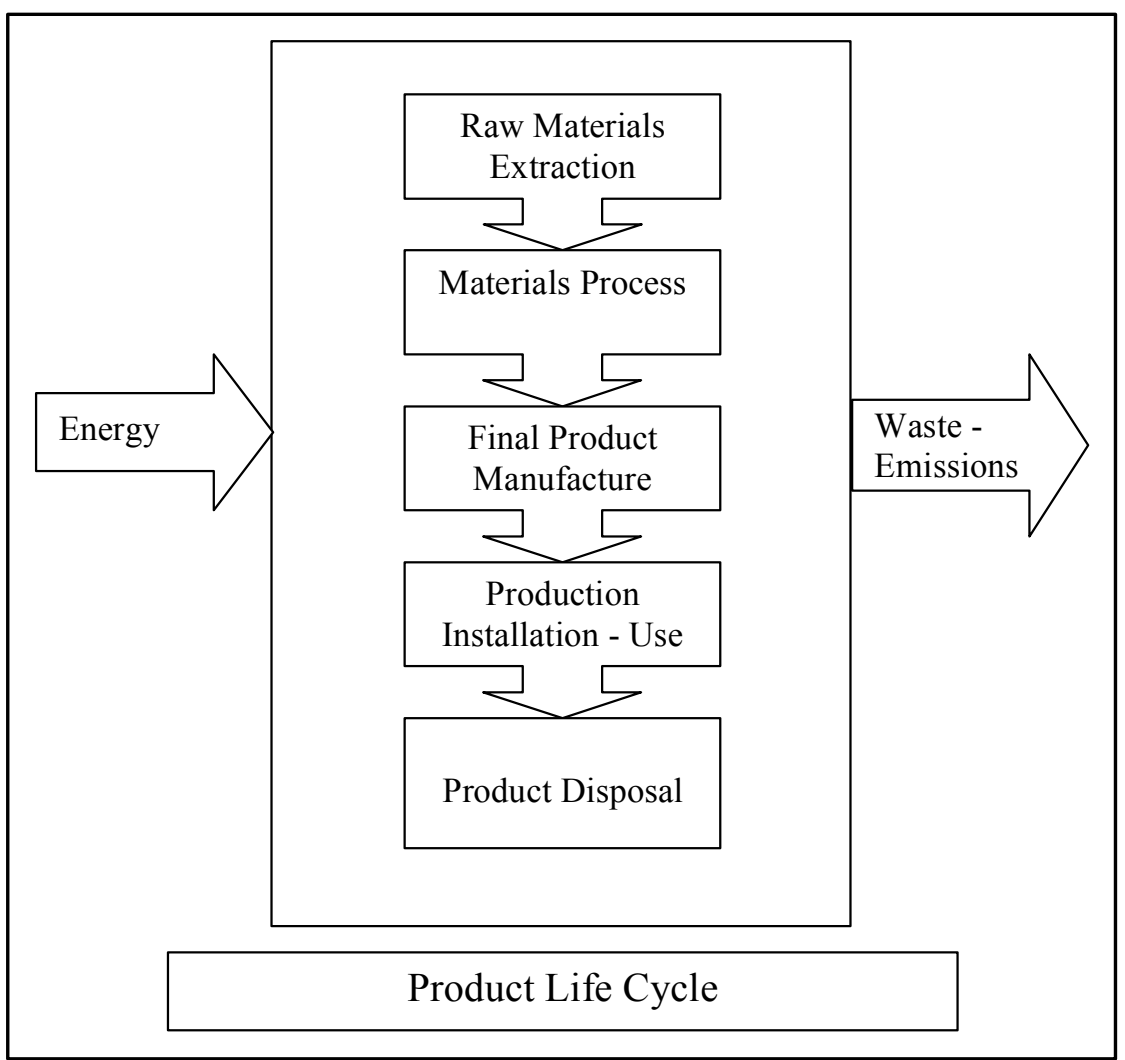

Figure 1. Product's Life Cycle and its transactions with the environment

Greece is one of the most successful countries world-wide in the use of solar thermal systems. The first systems were produced in mid 70's and by 1990 they had reached $1.760 .000 \mathrm{~m}^{2}$. Nowadays, more than 800.000 households (more than $25 \%$ of the total) use domestic solar hot water systems (DSHWS) and the country holds the second position in Europe not only in terms of installations but also in terms of production of DSHWS. In 2001 more than $40 \%$ of the solar collectors production was exported (European Solar Thermal Industry Federation, 2003).

The installed solar collector area per capita in Greece has been the highest in Europe for a number of years, reaching an average of 0,264 $\mathrm{m}^{2} /$ capita, tenfold higher the EU's average (European Solar Thermal Industry Federation, 2003), the figure including not only households but also hotel, industry, sports centre and greenhouse applications.

Although sun is the cleanest energy source available, important transactions with the environment are taking place over the whole lifecycle of a DSHWS (materials, manufacturing, transportation, utilization and final disposal). The consequences of these transactions include the depletion of natural sources, the greenhouse effect, acid rain etc. Therefore, and in view of the planned rapid expansion and enlargement of DSHWS utilization, it is necessary to evaluate solar technology, accounting for the indirect environmental impacts over its whole lifecycle (Figure 1). In this paper, the life cycle analysis (LCA) methodology is applied for the assessment of the environmental impact of DSHWS. A typical DSHWS, installed in a number of major Greek cities, distributed over the entire country, sized to fulfil the needs of different sizes of households, is evaluated, the evaluation accounting also for the environmental gain by the substitution of electricity, the main conventional energy used.

\section{LCA METHODOLOGY}

Life cycle assessment is a technique for assessing the environmental performance of a product, process or activity from "cradle to grave", i.e. from the extraction of raw materials to final disposal. Today's LCA originates from "net energy analysis" studies, first published in the 70s (Boustead., 1972; Hannon, 1972; and Sundstrom, 1973). These studies considered only energy consumption over the lifecycle of a product or a process. Some later studies included 
wastes and emissions (Lundolm and Sundstrom, 1985; and Boustead, 1989), but none of them went further than just quantifying materials and energy use. At this point it was clear that a more sophisticated approach to complex environmental issues was needed. As a result, in 1990, the Society for Environmental Toxicology and Chemistry (SETAC) initiated activities to define LCA and develop a general methodology for conducting the LCA studies. Soon afterwards, the International Organization for Standardization (ISO) started similar work on developing principles and guidelines on the LCA methodology (ISO/DIS 14040, 1997).

The methodology consists of four stages:

- First stage. The goal and the scope of the assessment are determined. The functional unit of the product is also defined in this stage.

- Second stage. Inventory analysis of the materials and of the processes end energy data (input to the system, output to the environment).

- Third stage. Consequences assessment and environmental impact calculation. The results of this stage allow for the comparative evaluation of different products.

- Fourth stage. Environmental impact interpretation of the distinct stages in product's life cycle, conclusions and suggestions for improvements.

While ISO methodology is still under development, the SETAC approach is widely accepted among LCA practitioners (Azapagic, 1999). In this paper, the "Eco-Indicator "99" methodology and the relevant database, covering a variety of manufacturing procedures and impacts, is adopted.

The Eco-Indicator of a material or process is a number, indicating the environmental impact of the material or process, based on data from a life cycle assessment. The standard "Eco-Indicator '99" values, termed Eco-Indicator points $(\mathrm{Pt})$, are dimensionless figures, representing the $1 / 1000$ of the annual environmental load of an average European inhabitant (Goedkoop et al., 2000). The "Eco-Indicator '99" methodology, used for the calculation of these standard values, conforms well to ISO-14042, although some deviations in details exist. The "Eco-Indicator '99" database provides standard values for (Goedkoop et al., 2000):

- Materials. Indicators for the production of materials needed for the final product. They include all the processes from the extraction of the raw material up to the last production stage. Transport processes along this path are also included. They are expressed in Pt/kg of material.

- Production. Indicators for the production processes during manufacturing as well as for the production of the energy needed. They are expressed in appropriate units (e.g. $\mathrm{Pt} / \mathrm{m}^{2}$ of rolled steel, $\mathrm{Pt} / \mathrm{kg}$ of extruded plastic etc.).

- Transportation. Indicators of the final product transportation from the manufacturing to the installation site. They include the emissions from the extraction and production of fuel up to the final usage of fuel on the vehicle. They are usually expressed in $\mathrm{Pt} / \mathrm{km}$-tonne, assuming an average loading factor of the vehicle and possibly an empty return trip.

- Energy generation. The indicators account for the power plant fuel extraction and preparation, fuel utilization for the electricity generation and also electricity transportation efficiency. They are expressed in $\mathrm{Pt} / \mathrm{kWh}$.

- Final disposal. The indicators are calculated according to the material and the final disposal method (incineration, landfill, recycling etc.) and they are expressed in $\mathrm{Pt} / \mathrm{kg}$.

\section{CASE STUDY}

DSHWS are assumed to be installed in 14 major cities, distributed over the country (Figure 2). The cities for installation were selected in order to cover a broad range of climate conditions, with more than $50 \%$ of the country's population (Table 1). The majority of DSHWS are manufactured close to Athens in Central Greece and in Thessaloniki in Northern Greece. For the purposes of the study, DSHWS are assumed to be manufactured only in the Thessaloniki industrial area. The DSHWS analyzed is the flat plate collector type (Figure 3), typical for Greek climate conditions. The collector consists of copper tubes extended with copper foils and, in order to boost absorbency, sprayed with black solar powder. A layer of expanded polyurethane (30 $\mathrm{mm}$ average thickness) is sprayed at the back of the collector for insulation. The sides of the collector are insulated with $20 \mathrm{~mm}$ thickness rock wool. The back cover of the collector is galvanized steel, while the sides consist of aluminum. The front area of the collector is 
covered with a single solar glass. The boiler (Figure 4) consists of a stainless steel mantle heat exchanger, with stainless steel sheet casing $(0,5$ mm thickness). A high density expanded polyurethane layer between boiler and casing is used for thermal insulation.

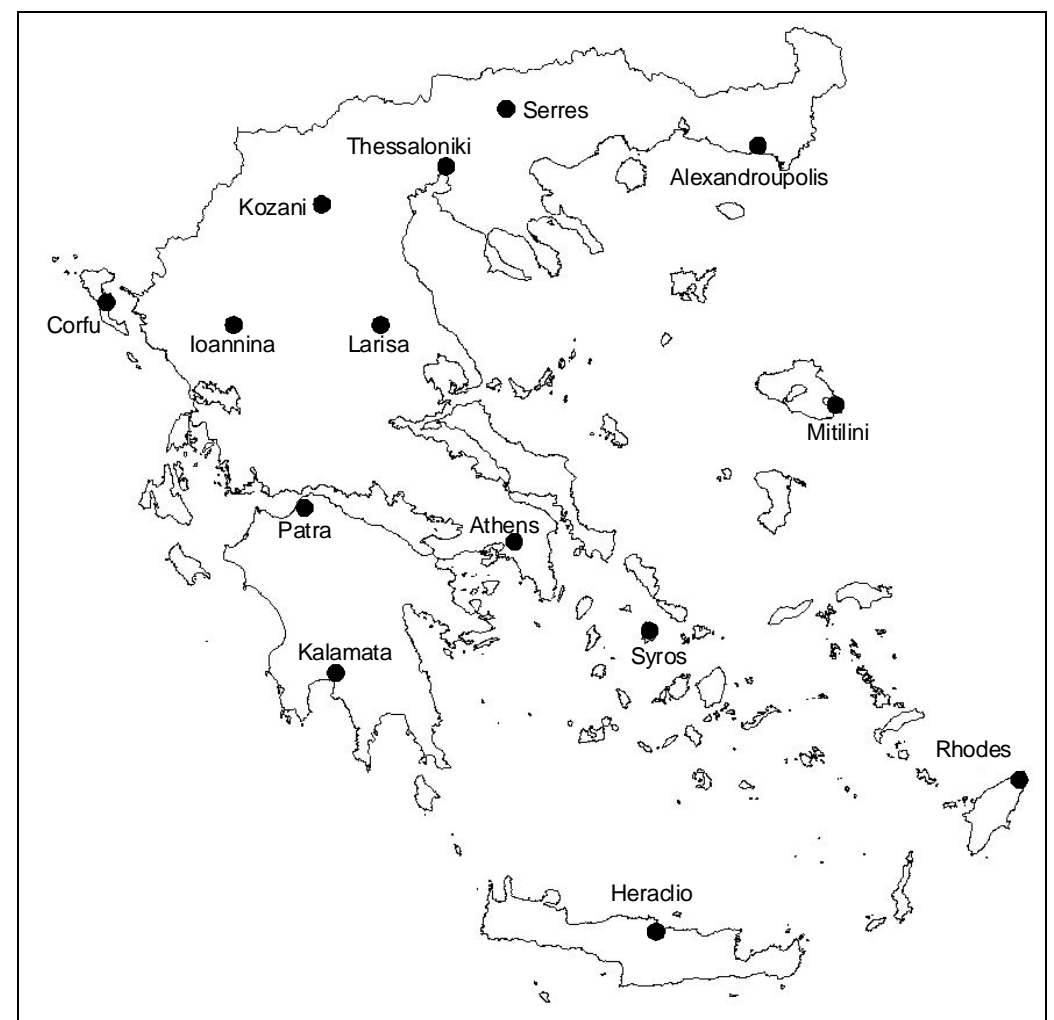

Figure 2. Location of the DSHWS installation sites

Table 1. Data for the installation locations analysed

\begin{tabular}{|c|c|c|c|c|c|c|c|c|}
\hline \multirow[b]{2}{*}{ Region } & \multirow[b]{2}{*}{ City } & \multicolumn{2}{|c|}{ Co-ordinates } & \multirow[b]{2}{*}{$\begin{array}{l}\text { Altitude } \\
\text { [m] }\end{array}$} & \multirow[b]{2}{*}{$\begin{array}{l}\text { Population } \\
\text { [x1000] } \\
\text { (Census } \\
2001)\end{array}$} & \multirow{2}{*}{$\begin{array}{l}\text { Annual Solar } \\
\text { Radiation, } \\
\text { Horizontal } \\
\text { plane } \\
{\left[\mathrm{kWh} / \mathrm{m}^{2}, \text { year }\right]}\end{array}$} & \multirow[b]{2}{*}{$\begin{array}{l}\text { Annual } \\
\text { Average Air } \\
\text { Temperature } \\
{\left[{ }^{\circ} \mathrm{C}\right]}\end{array}$} & \multirow{2}{*}{\begin{tabular}{|l|} 
Annual \\
Average \\
Grid Water \\
Temperature \\
{$\left[{ }^{\circ} \mathrm{C}\right]$} \\
\end{tabular}} \\
\hline & & Long. & Lat. & & & & & \\
\hline Crete & Heraclio & 35,33 & 25,14 & 47 & 137,8 & 1631 & 19,0 & 21,0 \\
\hline Dodecanese & Rhodes & 36,45 & 28,22 & 35 & 54,8 & 1686 & 19,0 & 19,2 \\
\hline Peloponnese & Kalamata & 37,04 & 22,11 & 5 & 56,9 & 1596 & 18,6 & 18,5 \\
\hline $\begin{array}{l}\text { Cyclades } \\
\text { Central }\end{array}$ & Syros & 37,45 & 24,93 & 9 & 14,1 & 1621 & 18,5 & 18,8 \\
\hline Greece & Athens & 37,98 & 23,80 & 107 & 3689,5 & 1581 & 17,8 & 17,8 \\
\hline Peloponnese & Patra & 38,24 & 21,73 & 15 & 164,5 & 1479 & 17,8 & 18,5 \\
\hline North Aegean & Mitilini & 39,11 & 25,55 & 3 & 35,5 & 1539 & 17,8 & 18,7 \\
\hline Ionian & Corfu & 39,63 & 19,92 & 132 & 41,1 & 1493 & 17,7 & 17,1 \\
\hline Thessaly & Larissa & 39,63 & 22,42 & 73 & 124,4 & 1433 & 16,2 & 17,0 \\
\hline Epirus & Ioannina & 39,66 & 20,86 & 483 & 70,2 & 1357 & 14,7 & 14,2 \\
\hline Macedonia & Kozani & 40,32 & 21,80 & 810 & 48,1 & 1361 & 16,1 & 14,7 \\
\hline Macedonia & Thessaloniki & 40,64 & 22,95 & 30 & 831,7 & 1403 & 16,0 & 15,6 \\
\hline Thrace & Alexandroupolis & 40,86 & 25,88 & 10 & 52,6 & 1368 & 16,5 & 15,4 \\
\hline Macedonia & Serres & 41,10 & 23,55 & 32 & 56,1 & 1380 & 15,3 & 16,0 \\
\hline
\end{tabular}




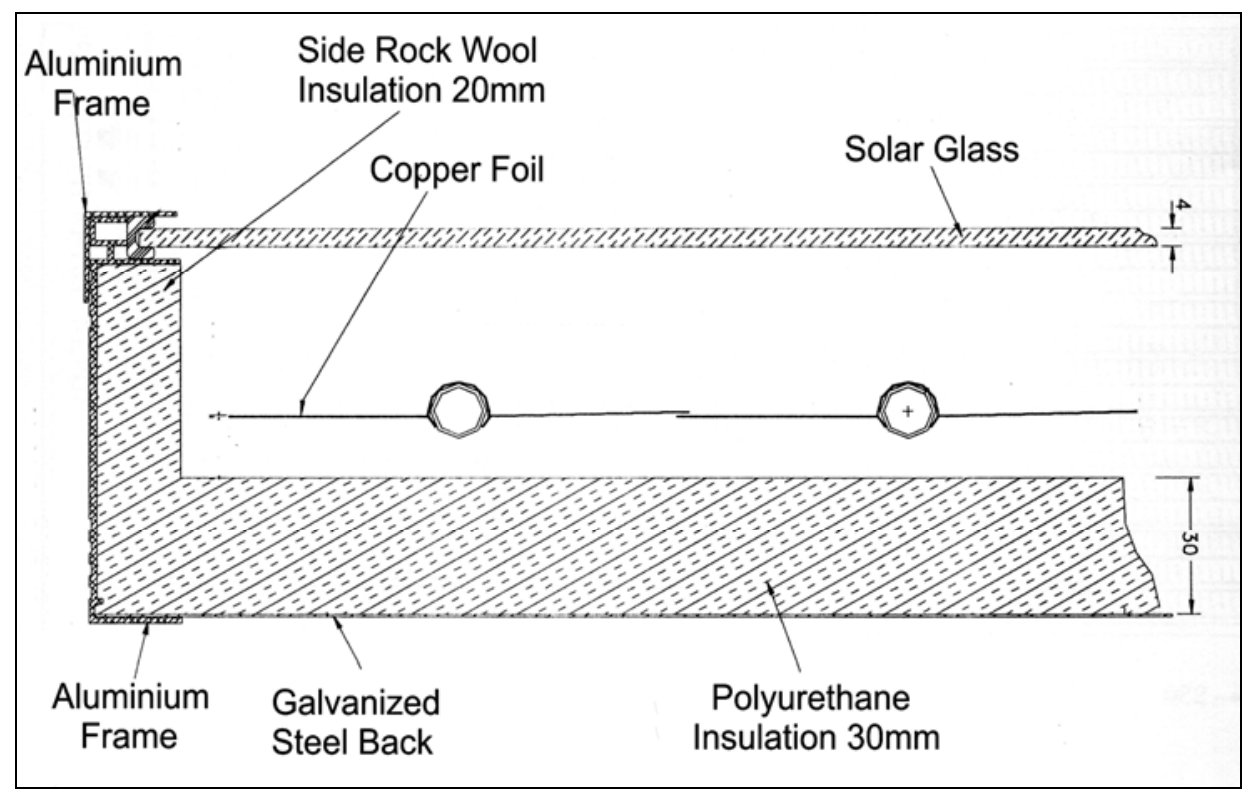

Figure 3. Cross section of the solar collector

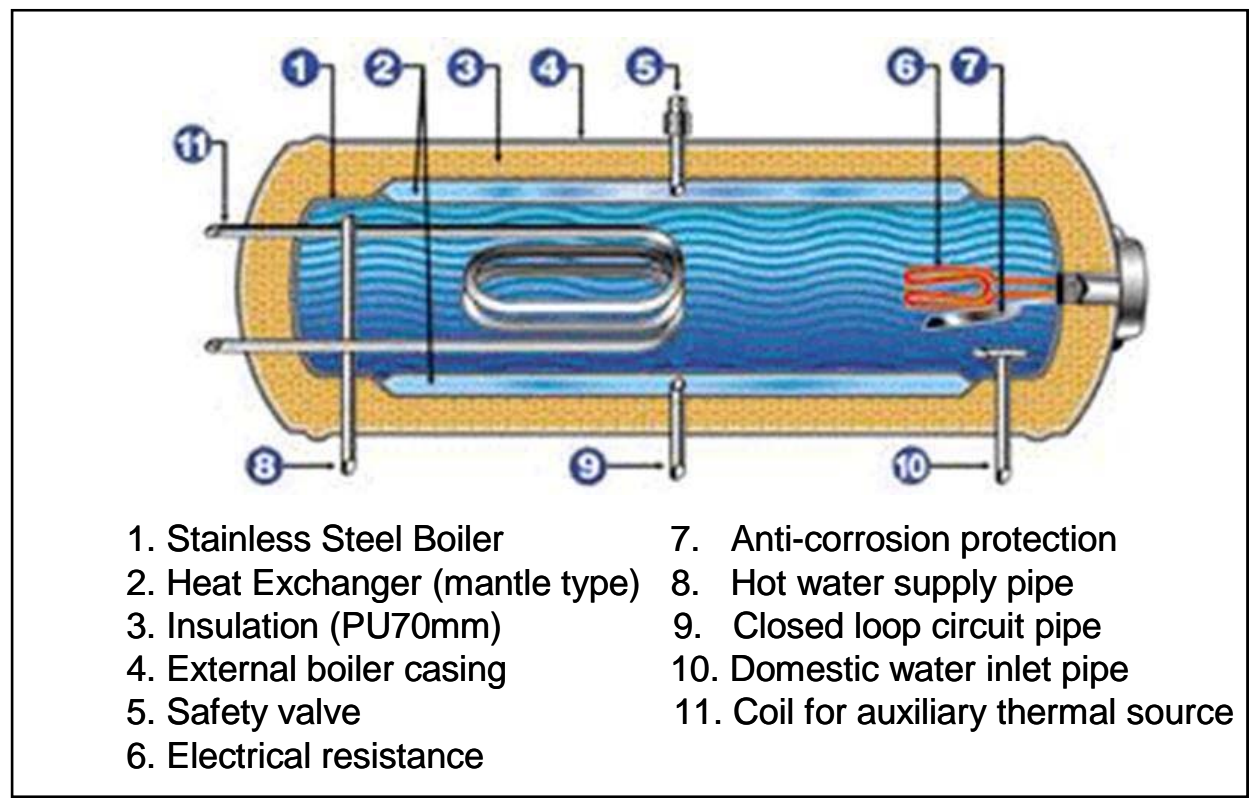

Figure 4. Cross section of the boiler

The inclination of the collector is set at $45^{\circ}$ for all locations, well within the recommendation (latitude $\pm 15^{\circ}$ ) of the literature (Lunde, 1979).

The households considered are two, three, four and five person's families and the corresponding DSHWS sizes usually used are listed in Table 2, with the technical characteristics summarized in Table 3.

Normally, domestic hot water is produced by the use of electrical heaters. Consequently, and for the purposes of this analysis, it is accepted that DSHWS substitutes electricity. Since the case is only partial electricity substitution, the electrical heater is considered as already existing; therefore its manufacturing environmental impact is not accounted for.

\section{RESULTS}

LCA requires a detailed description of the materials and the procedures related to a product. Figure 5 shows a simplified LCA chart for a DSHWS. Based on the technical information of the systems analyzed, the quantities for each of the materials and procedures listed in Figure 5 can be estimated and then translated to environmental impact $(\mathrm{Pt})$, with the "EcoIndicator "99" database and methodology. 
Table 2. Systems Analysed

\begin{tabular}{|c|c|c|c|c|c|c|}
\hline Household & \multicolumn{6}{|c|}{ DSHWS Size } \\
\cline { 2 - 7 } Size & $2 \mathrm{~m}^{2} \backslash 1201$ & $2 \mathrm{~m}^{2} \backslash 1801$ & $4 \mathrm{~m}^{2} \backslash 1801$ & $4 \mathrm{~m}^{2} \backslash 2001$ & $6 \mathrm{~m}^{2} \backslash 1801$ & $6 \mathrm{~m}^{2} \backslash 2001$ \\
\hline 2 & $\mathrm{x}$ & $\mathrm{x}$ & & & & \\
3 & & $\mathrm{x}$ & $\mathrm{x}$ & & & \\
4 & & & $\mathrm{x}$ & & $\mathrm{x}$ & \\
5 & & & & $\mathrm{x}$ & & $\mathrm{x}$ \\
\hline
\end{tabular}

Table 3. Characteristics of the analysed DSHWS

\begin{tabular}{|l|l|}
\hline Collector Type & Flat-Plate, Copper Tube with Copper Foils \\
Glazing & Single Glass \\
Selective Paint & Black Solar Powder \\
$\mathrm{F}_{\mathrm{R}} \mathrm{U}_{\mathrm{L}}$ & $8,42 \mathrm{~W} / \mathrm{m}^{2} \mathrm{~K}$ \\
$\mathrm{~F}_{\mathrm{R}}(\tau \alpha)_{\mathrm{n}}$ & 0,76 \\
Collector Inclination & $45^{\circ}$ \\
Collector Area & $2-4-6 \mathrm{~m}^{2}$ \\
Tank Capacity & $120-180-2001$ \\
Hot Water Temperature & $50{ }^{\circ} \mathrm{C}$ \\
\hline
\end{tabular}

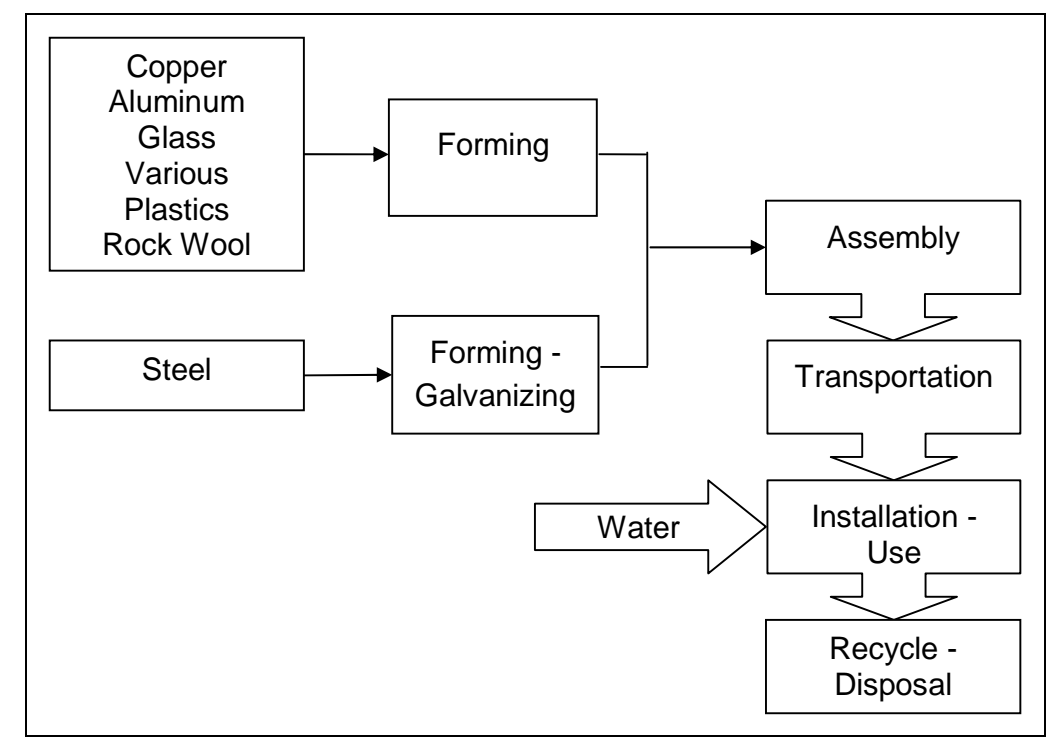

Figure 5. Simplified life cycle flow chart of a DSHWS

For the transportation of the final product it is accepted that in the case that the distance between manufacturing and installation site is less than $20 \mathrm{~km}$ (i.e. for installations in Thessaloniki area) a 3,5 t truck is used with an environmental impact of $140 \mathrm{mPt} / \mathrm{km}$-tonne. For longer distances a $28 \mathrm{t}$ truck is used with an impact of $22 \mathrm{mPt} / \mathrm{km}$-tonne, including return trip (average European value with $40 \%$ load). For sea transport an impact of $5,1 \mathrm{mPt} / \mathrm{km}$-tonne is used. The systems are assumed to be transported from Thessaloniki port to Mitilini by sea. For Corfu, the product is transported by land to the port of Igoumenitsa (opposite of Corfu) and then by ship to the island, while for Rhodes, Syros and Heraklion the systems are transported by land to Piraeus port (seaport of Athens) and then by ship to the corresponding ports (see also Figure 2).

The results of this calculation are listed in Table 4 (the figures in parenthesis are the transportation contribution, in percent). From the data in Table 4 it is clear that the environmental impact of the DSHWS varies from 74,90 to $142,27 \mathrm{Pt}$, depending on the system size and site of installation. The transportation impact depends on the distance between manufacturing and installation site and on the transportation means, but in any case it is practically 
Table 4. DSHWS total environmental impact [Pt] including transportation. In parenthesis the contribution of transportation to the total impact [\%]

\begin{tabular}{|l|c|c|c|c|c|c|}
\hline \multirow{2}{*}{ City } & \multicolumn{7}{|c|}{ DSHWS sizes } \\
\cline { 2 - 7 } & $2 \mathrm{~m}^{2} \backslash 1201$ & $2 \mathrm{~m}^{2} \backslash 1801$ & $4 \mathrm{~m}^{2} \backslash 1801$ & $4 \mathrm{~m}^{2} \backslash 2001$ & $6 \mathrm{~m}^{2} \backslash 1801$ & $6 \mathrm{~m}^{2} \backslash 2001$ \\
\hline Heraclio & $76,31(2,17)$ & $87,34(2,10)$ & $111,44(2,35)$ & $116,60(2,31)$ & $136,50(2,51)$ & $141,66(2,47)$ \\
Rhodes & $76,40(2,28)$ & $87,44(2,21)$ & $111,58(2,47)$ & $116,75(2,43)$ & $136,69(2,64)$ & $141,85(2,60)$ \\
Kalamata & $76,60(2,53)$ & $87,66(2,45)$ & $111,90(2,74)$ & $117,07(2,70)$ & $137,10(2,93)$ & $142,27(2,89)$ \\
Syros & $76,28(2,13)$ & $87,30(2,06)$ & $111,39(2,30)$ & $116,55(2,16)$ & $136,43(2,46)$ & $141,59(2,42)$ \\
Athens & $76,08(1,87)$ & $87,08(1,81)$ & $111,07(2,02)$ & $116,22(1,99)$ & $136,02(2,16)$ & $141,16(2,13)$ \\
Patra & $76,01(1,77)$ & $87,00(1,72)$ & $110,96(1,92)$ & $116,10(1,89)$ & $135,87(2,05)$ & $141,01(2,02)$ \\
Mitilini & $75,27(0,81)$ & $86,18(0,78)$ & $109,79(0,88)$ & $114,90(0,86)$ & $134,34(0,94)$ & $139,45(0,92)$ \\
Corfu & $75,72(1,39)$ & $86,67(1,35)$ & $110,50(1,51)$ & $115,63(1,48)$ & $135,26(1,61)$ & $140,39(1,59)$ \\
Larisa & $75,09(0,57)$ & $85,97(0,55)$ & $109,50(0,61)$ & $114,60(0,60)$ & $133,96(0,66)$ & $139,06(0,65)$ \\
Ioannina & $75,42(1,01)$ & $86,35(0,98)$ & $110,04(1,10)$ & $115,15(1,08)$ & $134,66(1,17)$ & $139,78(1,16)$ \\
Kozani & $75,01(0,46)$ & $85,89(0,45)$ & $109,38(0,50)$ & $114,47(0,49)$ & $133,80(0,54)$ & $138,89(0,53)$ \\
Thessaloniki & $75,01(0,47)$ & $85,89(0,45)$ & $109,38(0,51)$ & $114,48(0,50)$ & $133,81(0,54)$ & $138,90(0,53)$ \\
Alexandroupolis & $75,59(1,23)$ & $86,53(1,19)$ & $110,30(1,33)$ & $115,42(1,31)$ & $135,00(1,42)$ & $140,13(1,40)$ \\
Serres & $74,90(0,32)$ & $85,77(0,31)$ & $109,21(0,35)$ & $114,30(0,34)$ & $133,58(0,37)$ & $138,67(0,37)$ \\
\hline
\end{tabular}

Table 5. Annual Solar Coverage ( $f$ ) for each location, family size and DSHWS

\begin{tabular}{|l|c|c|c|c|c|c|c|c|}
\hline \multirow{2}{*}{ City } & \multicolumn{2}{|c|}{ 2 persons } & \multicolumn{2}{c|}{ 3 persons } & \multicolumn{2}{c|}{ 4 persons } & \multicolumn{2}{c|}{$\mathbf{5}$ persons } \\
\cline { 2 - 8 } & $2 \mathrm{~m}^{2} \backslash 1201$ & $2 \mathrm{~m}^{2} \backslash 1801$ & $2 \mathrm{~m}^{2} \backslash 1801$ & $4 \mathrm{~m}^{2} \backslash 1801$ & $4 \mathrm{~m}^{2} \backslash 1801$ & $6 \mathrm{~m}^{2} \backslash 1801$ & $4 \mathrm{~m}^{2} \backslash 2001$ & $6 \mathrm{~m}^{2} \backslash 2001$ \\
\hline Heraclio & 0,690 & 0,717 & 0,581 & 0,792 & 0,717 & 0,819 & 0,651 & 0,772 \\
Rhodes & 0,720 & 0,745 & 0,602 & 0,821 & 0,745 & 0,847 & 0,676 & 0,801 \\
Kalamata & 0,680 & 0,708 & 0,562 & 0,792 & 0,708 & 0,821 & 0,635 & 0,770 \\
Syros & 0,666 & 0,693 & 0,549 & 0,777 & 0,693 & 0,806 & 0,621 & 0,755 \\
Athens & 0,660 & 0,686 & 0,545 & 0,770 & 0,686 & 0,799 & 0,616 & 0,748 \\
Patra & 0,624 & 0,651 & 0,512 & 0,739 & 0,651 & 0,769 & 0,582 & 0,716 \\
Mitilini & 0,641 & 0,669 & 0,532 & 0,747 & 0,669 & 0,775 & 0,601 & 0,727 \\
Corfu & 0,622 & 0,649 & 0,509 & 0,735 & 0,649 & 0,765 & 0,578 & 0,713 \\
Larisa & 0,581 & 0,608 & 0,474 & 0,695 & 0,608 & 0,726 & 0,541 & 0,672 \\
Ioannina & 0,513 & 0,540 & 0,413 & 0,629 & 0,540 & 0,662 & 0,475 & 0,604 \\
Kozani & 0,532 & 0,559 & 0,427 & 0,651 & 0,559 & 0,686 & 0,491 & 0,625 \\
Thessaloniki & 0,563 & 0,590 & 0,456 & 0,679 & 0,590 & 0,712 & 0,521 & 0,655 \\
Alexandroupoli & 0,541 & 0,568 & 0,436 & 0,659 & 0,568 & 0,693 & 0,500 & 0,634 \\
Serres & 0,539 & 0,566 & 0,436 & 0,654 & 0,566 & 0,687 & 0,500 & 0,630 \\
\hline
\end{tabular}

negligible, as it is always below $3 \%$ of the total. The contribution of individual components of the DSHWS to its total environmental impact has been analysed and presented in previous work (Tsilingiridis et al., 2004). In case that the manufacturing site of the DSHWS was in Athens, the transportation impact would be lower for the southern and island installation sites, and higher for the cities of Northern Greece. In all cases the impact remains practically negligible, less than $3,5 \%$ of the total.Using the f-chart method makes it possible to calculate the annual percentage of solar coverage of load for domestic hot water production (Duffie and Beckman,
1991). The required data (air temperatures, grid water temperatures and solar radiation) are taken from the literature (Pelekanos, 1982). The monthly variation of solar radiation for the cities in study on $45^{\circ}$ plane is shown in Figure 6. Solar coverage results are listed in Table 5. As it can be seen, for the same location and collector area, increasing the tank size from 120 to 1801 , i.e. by $50 \%$, results only in a slightly increase of coverage, 3,5 to $5 \%$, depending on the location. With the same tank size, doubling the collector area from 2 to $4 \mathrm{~m}^{2}$, results in an average coverage increase of $45 \%$, while this increase is reduced to $21 \%$ when the collector area is 
increased by $50 \%$, from 4 to $6 \mathrm{~m}^{2}$. The influence of location and collector size is more apparent in Figure 7, where the maximum and minimum coverage are plotted as a function of the solar radiation. The data of Table 5 translated to annual energy values are listed in Table 6 and the environmental cost, calculated as the ratio of the environmental impact over the total energy covered by the DSHWS, is listed in Table 7. Even though the environmental impact increases with the size of the DSHWS, for the same location and household size, the environmental cost decreases with the size of the collector, due to the resulting increased solar coverage.

As already mentioned, hot water is normally produced with electrical heaters. DSHWS undertakes a part of this duty, as listed in Table 6. Assuming an overall efficiency of $95 \%$ for the electrical heater and using the "Eco-Indicator '99" standard value for electricity (61 mPt/kWh), the total environmental impact for the 15 years hot water production can be calculated from the data of Table 6 for the electrical only and for the combined DSHWS plus electrical heater systems, taking into account the DSHWS production impacts, the results listed in Table 8 .

Figure 8 shows the overall environmental impact of the hot water production with electrical heater for the 15 years period and the net environmental gain achievable with the combined electrical heater plus DSHWS, expressed as percentage. The lower gain, for the systems we have analysed, results for 2 persons household and it is roughly $50 \%$ for the cities of Ioannina, Kozani and Serres, all of them in the northern part of the

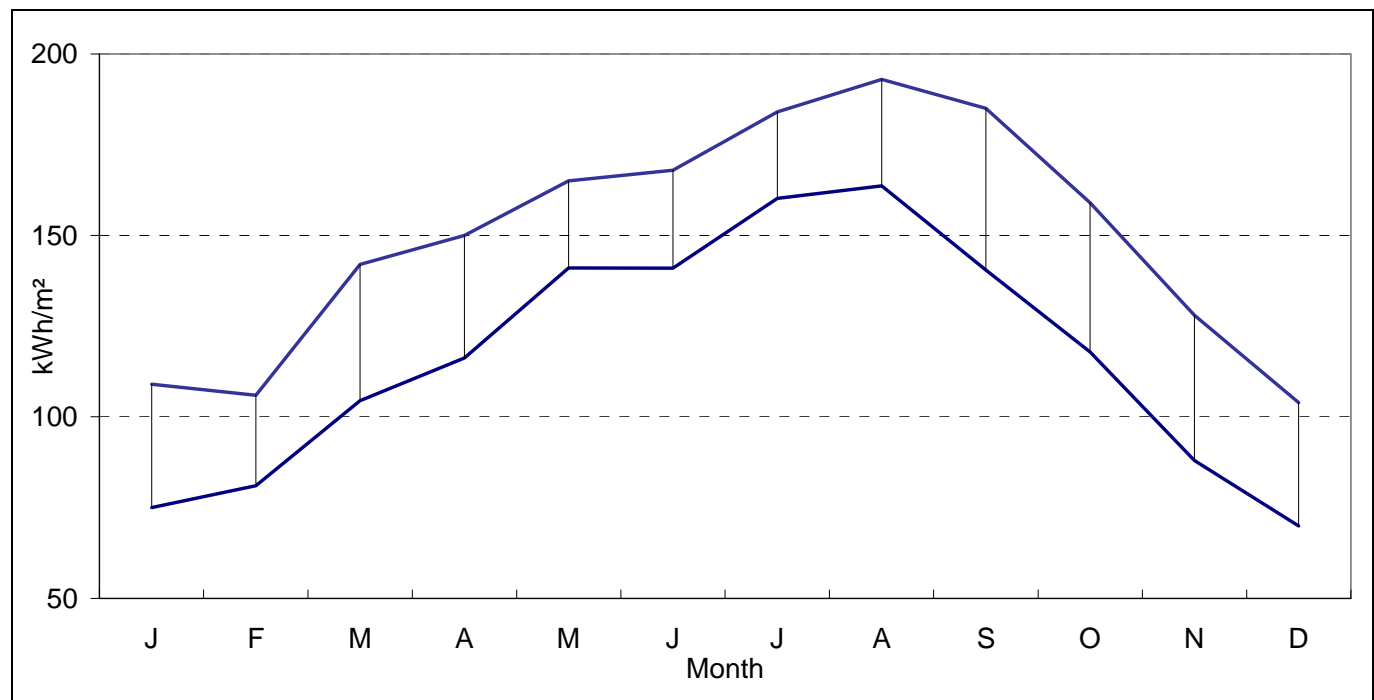

Figure 6. Solar radiation on a $45^{\circ}$ plane. Range for all cities under consideration

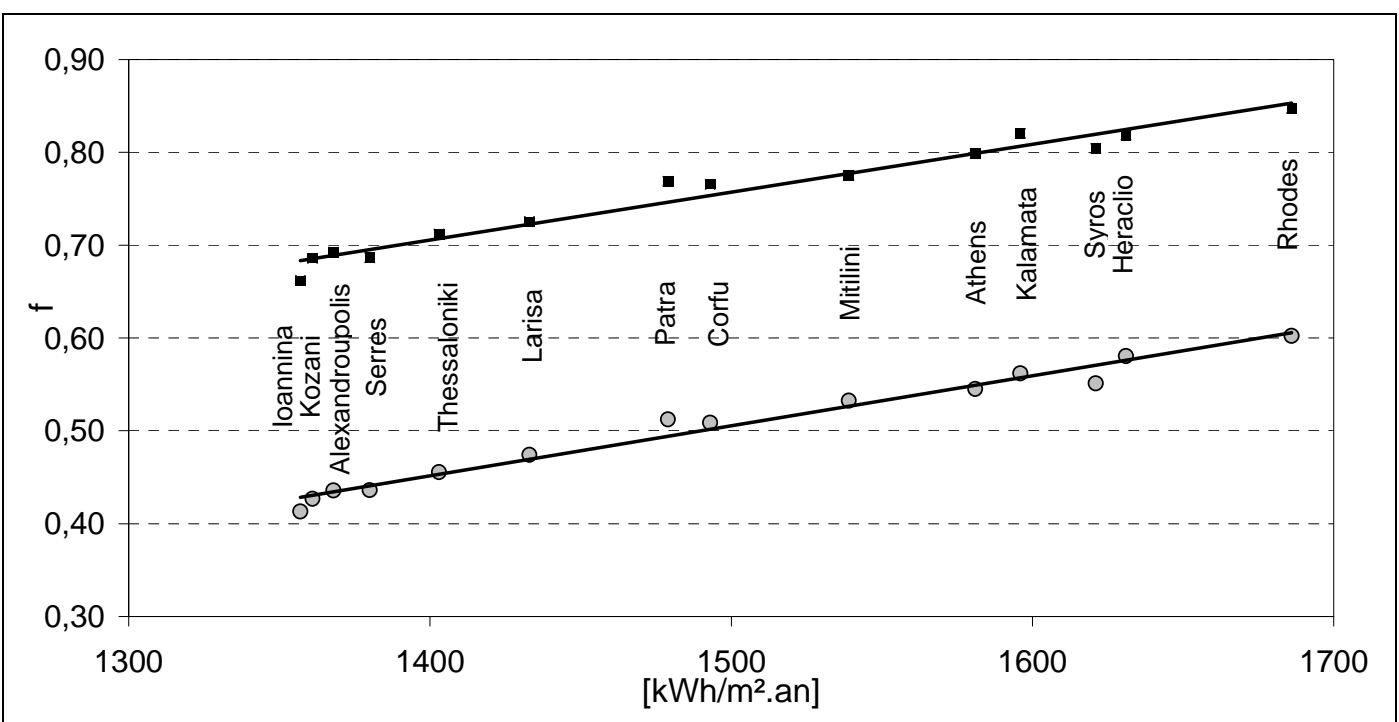

Figure 7. Maximum ( $6 \mathrm{~m}^{2} / 1801,4$ persons) and minimum $\left(2 \mathrm{~m}^{2} / 1801,3\right.$ persons) annual solar coverage in correlation with solar radiation 


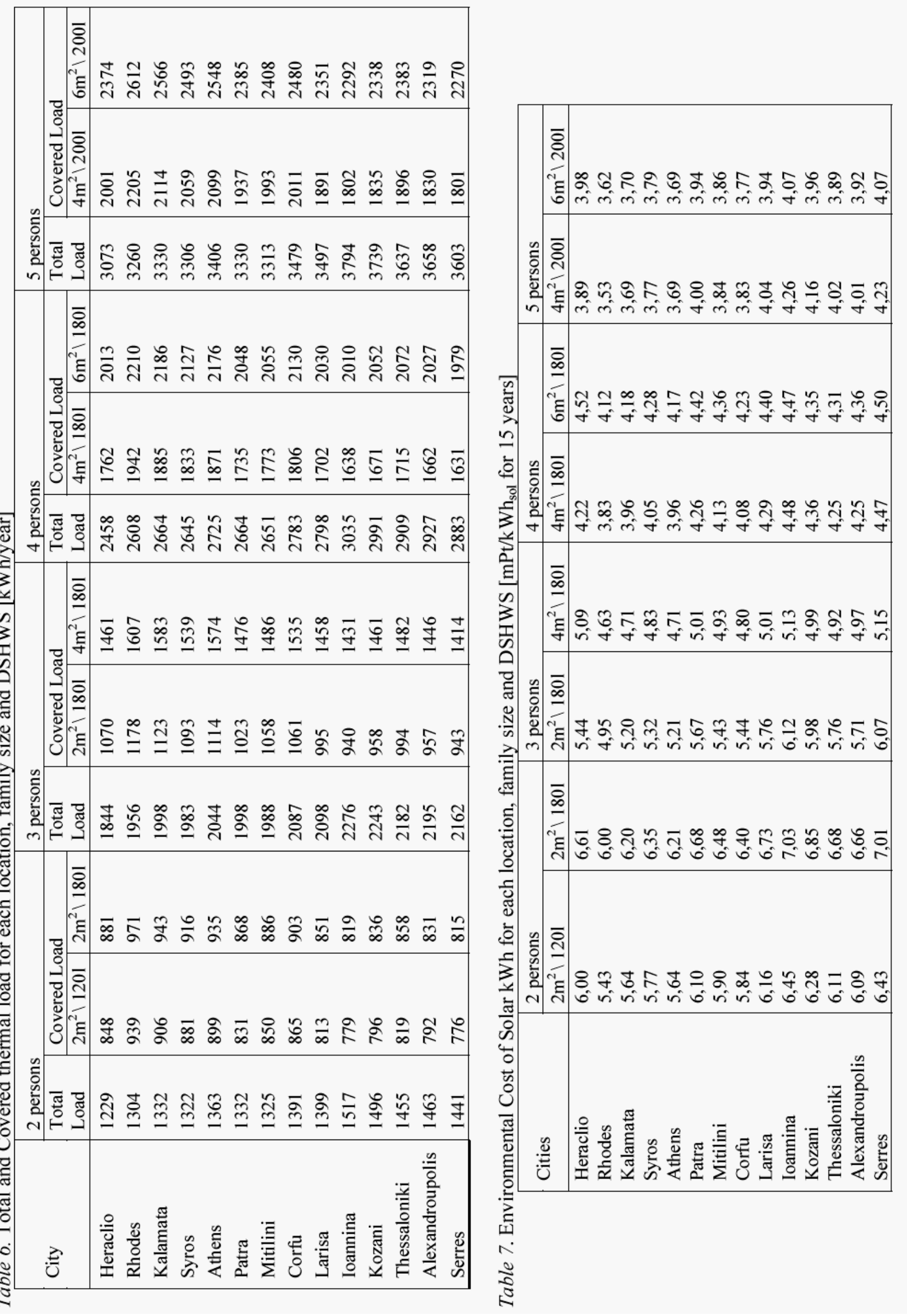




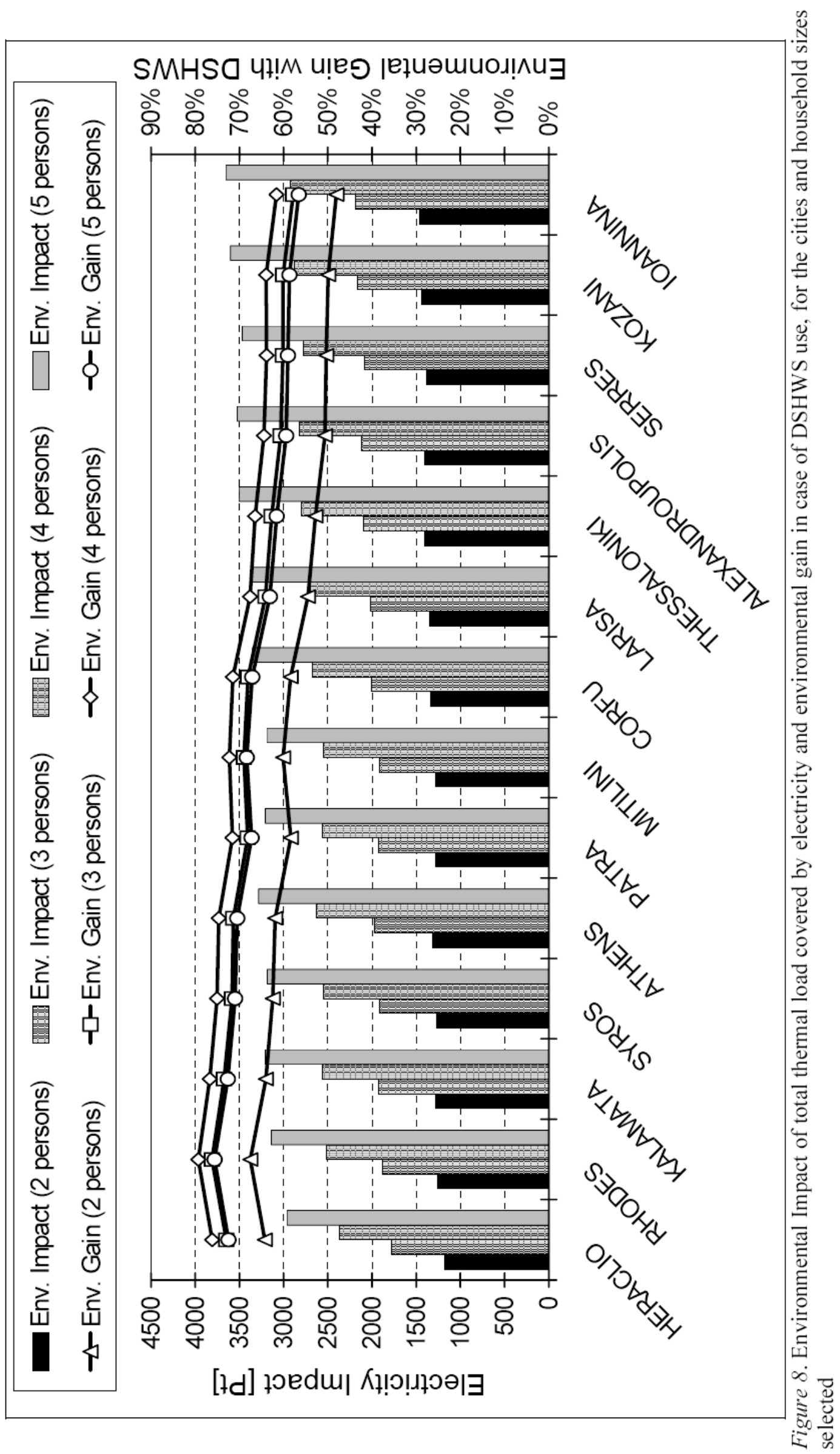




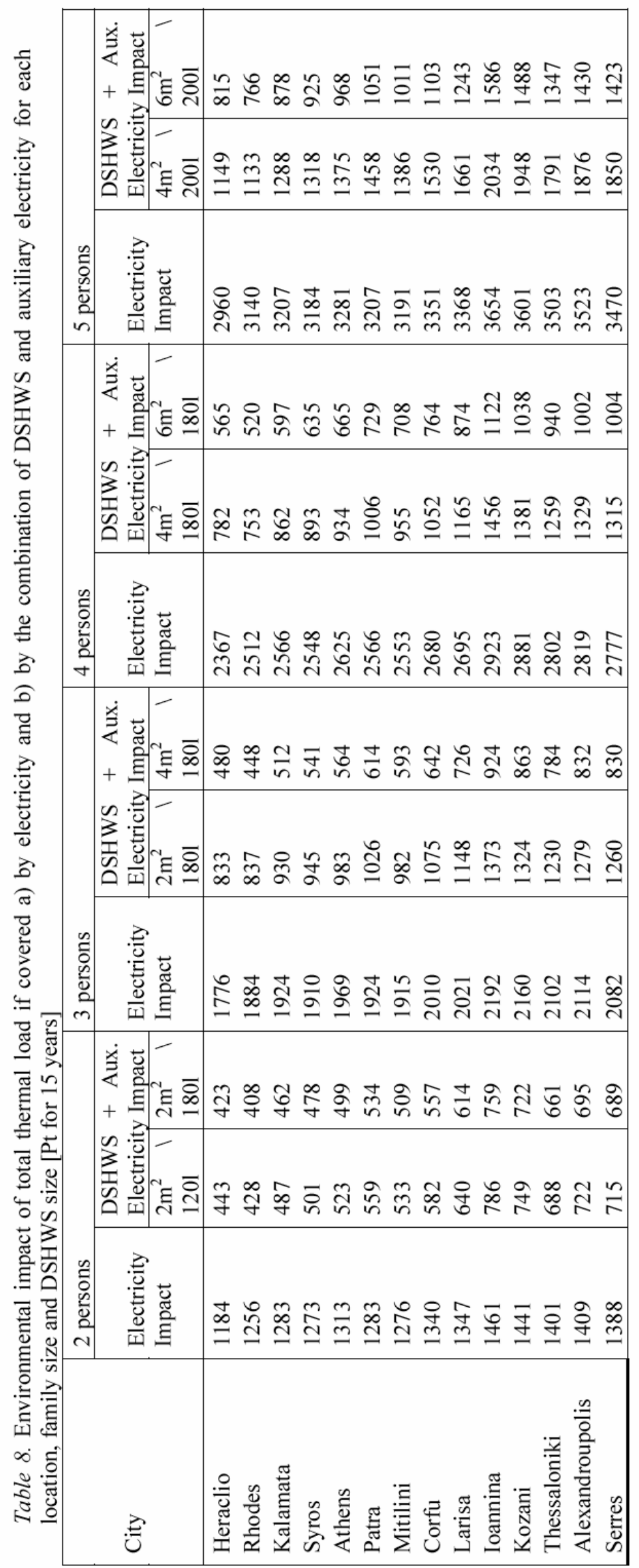


country, with the lowest solar radiation and ambient temperature.

The highest gain results for the 4 persons household and for the installation sites with the highest solar radiation and temperatures, as expected. It is roughly $80 \%$, remaining however above $60 \%$ for the lower radiation sites as well. It is worth noticing at this point that the "EcoIndicator '99" standard value for electricity production used in this paper is the country's average, including both lignite and diesel oil power plants. Mainland cities are connected to the national power supply network, operating mainly on lignite, while in the islands electricity is locally produced in diesel oil plants. This means that the electricity consumption in mainland has more severe environmental impacts than in islands, and a more detailed calculation can reveal the difference, making DSHWS even more environmental friendly in mainland.

\section{CONCLUSIONS}

The lifecycle environmental impact of a DSHWS is between 75 and $142 \mathrm{Pt}$, depending on the system size and the distance and means of transport between manufacturing and installation sites. However transportation impact was found not to exceed $3 \%$ of the total in all cases and it can therefore be considered insignificant.

The environmental impact increases with the size of the DSHWS, for the same location and household size, but the environmental cost (ratio of the environmental impact from the DSHWS over the total energy covered by its use) decreases with the size of the collector, due to the resulting increased solar coverage.

The efficiency of solar systems, and the relevant environmental gain, depends not only on the geographical position and the solar radiation of the installation site but also on other parameters, like ambient air and grid water temperatures.

The production and utilization of a DSHWS has a net environmental gain over electricity of at least $670 \mathrm{Pt}$ and up to $2145 \mathrm{Pt}$ (50 to $80 \%$ respectively). These figures do not include the impact from the production of the electrical heaters, since their installation cannot be avoided. Even in the worst case examined (2 persons household in the less favourable for solar applications site in northern Greece) the overall net environmental gain resulting from the utilization of DSHWS is at least $50 \%$, proving that solar energy is a truly clean form of energy. Boustead, 1972; Hannon, 1972; Sundstrom, 1973.

\section{REFERENCES}

Azapagic A. (1999), Life Cycle Assessment and its application to process selection, design and optimization, Chemical Engineering Journal, 73, 1-21.

Boustead I. (1972), The Milk Bottle, Open University Press, Milton Keynes.

Boustead I. (1989), Environmental Impact of the Major Beverage Packaging Systems - U.K. data 1986 in response to the EEC directive 85/339, INCPEN, London, 1-4.

Duffie J.A. and Beckman W.A. (1991), Solar Engineering of Thermal Processes, Wiley Publication.

European Commission (1997), White Paper: Energy for the future: Renewable sources of energy.

European Commission (1999), Green Paper: Towards a European strategy for the security of energy supply.

European Solar Thermal Industry Federation (2003), Sun in Action II, Vol.2.

Goedkoop M., Effting S. and Collingo M. (2000), The Eco-Indicator'99 - A damage oriented method for Life Cycle Impact Assessment - Manual for Designers, Pre Consultants B.V., Second Edition.

Hannon B. (1972), System Energy and Recycling: A Study of the Beverage Industry, Center for Advanced Computation, University of Illinois, Urbana, IL.

ISO/DIS 14040 (1997), Environmental Management - Life Cycle Assessment-Part 1: Principles and Framework.

Lunde P. J. (1979), Solar Energy, pp 23-115.

Lundolm M.P. and Sundstrom G. (1985), Resource and Environmental Impact of Tetra Brik Carton and Refillable and Non-Refillabel Glass Bottles, AB Tetra Pak, Malmo. 
Pelekanos A. (1982), Meteorological Data for implementation of solar applications in various cities in Greece, Proceeding of 1st National Conference for the Renewable Energy Sources, Volume A', Institute of Solar Technology, Thessaloniki. (In Greek).

Sundstrom G. (1973), Investigation of the energy requirements from raw materials to garbage treatment for 4 Swedish Beer Packaging Alternatives, Report for Rigello Park AB, Sweden.

Tsilingiridis G., Martinopoulos G. and Kyriakis N. (2004), Environmental impact of a domestic solar flat-plate thermosyphonic system during its life cycle in comparison with conventional energy forms, Renewable Energy, 29, pp 1277-1288. 